\title{
Editorials
}

\section{Prescribing gluten-free foods in general practice}

The Department of Health and Social Care has recently published their consultation outcome regarding the availability of glutenfree foods (GFF) on NHS prescriptions. ${ }^{1}$ Following an unprecedented number of responses from patients, healthcare professionals, and professional bodies, the Government has decided to continue to provide GFF on prescription but restrict the products available to breads and mixes. This favoured option by the majority of consultation responders has now proceeded to formal ratification, through an amendment to the NHS Regulations 2004, Schedule 1. In this editorial, we discuss the controversies that have existed regarding prescription of GFF in coeliac disease where the gluten-free diet is the treatment, and discuss the future implications that this decision may have on both patients and the NHS.

\section{HISTORY OF GFF PRESCRIPTIONS}

GFFproducts havebeenavailablein the UKvia prescription for those medically diagnosed with coeliac disease for $>50$ years, with the aim of supporting dietary adherence and reducing complications. In recent years, these prescriptions were restricted to staple foods, approved by the Advisory Committee on Borderline Substances (ACBS). The National Prescribing Guidelines endorsed by both the Primary Care Society for Gastroenterology and the British Dietetic Association set out recommendations to healthcare professionals on the quantity of gluten-free staple foods that may be prescribed. ${ }^{2}$ These allowances (in units) were determined by an individual's age and sex (for example, male 19-59 years $=18$ units, female $19-74$ years $=14$ units) and based upon:

- continued consumption of naturally gluten-free foods (such as potato and rice);

- data from the National Diet and Nutrition Surveys; and

- the Eatwell Guide for balanced eating (https://www.nhs.uk/live-well/eat-well/ the-eatwell-guide/)

These guidelines, first launched in 2004, offer equitable allowances for all UK patients, however costs to individuals vary.

\section{the Government has decided to continue to provide GFF [gluten-free food] on prescription but restrict the products available to breads and mixes.}

In England, people with coeliac disease pay prescription charges lunless they meet exemption criteria), while prescriptions in Scotland, Northern Ireland, and Wales are free. This method of support differs to some other countries where government subsidies ffor example, in Italy and Argentinal or tax deductibility of excess costs (for example, in the US and Canada) are being used. ${ }^{3,4}$

\section{RECENT CONTROVERSIES IN GFF PRESCRIPTIONS AND FAKE NEWS}

In 2014 NHS PrescQIPP raised concerns that the annual cost of prescriptions for GFF products in England was E24.7 million. ${ }^{5}$ Recommendations were made to restrict prescriptions to 8 units of bread and flour only, with the ambition of saving potentially E10 million. ${ }^{5}$ This started a trend for restricting access to GFF on prescription by a number of clinical commissioning groups (CCGs). A geographical variation in care subsequently developed within England that differed to NHS practices in Scotland, Northern Ireland and Wales where national prescribing guidelines are still followed.

These local decisions and concerns about the variation in gluten-free prescribing policies were widely discussed in both the medical literature and the national press. ${ }^{6}$ These included concerns about the cost of GFF products, NHS procurement practices and the appropriate use of a GPs time in prescribing GFF products. In relation to costs, the Daily Mail ran a front-page headline on the 17 August 2015 deriding a E116 million spend on gluten-free junk food on prescription. This article fuelled further misconceptions about GFF prescriptions and was later retracted due to significant factual inaccuracie. The true spend was: €26.8 million on staple food items only las based on 2014 data).?

\section{THE DEPARTMENT OF HEALTH AND SOCIAL CARE CONSULTATION}

A national public consultation was conducted by the Department of Health and
Social Care between the 31 March and the 22 June 2017. The consultation suggested that the spend of $€ 25.7$ million las based on 2015 datal on GFF prescriptions could be redeployed into other areas of the NHS. The NHS was unable to apply restrictions to GFF prescriptions as they lacked statutory authority to do this, with prescribing responsibilities laid down in national prescribing legislation that only Government could amend. A national public consultation was conducted by the Department of Health \& Social Care between 31 March and 22 June 2017, where views on three options were sought. The options included:

- make no changes to GFF prescribing;

- end all GFF prescribing in primary care by adding GFF products to Schedule 1; and

- restrict to selected GFF products (namely bread and mixes) on prescription.

Holding a national consultation on the issue was supported by both NHS England and clinical commissioners. Lauren Hughes, Director of Clinical Policy and Operations, NHS England, stated:

'The purpose of this review is to develop guidance at a national level that will support CCGs locally to manage their resources and reduce the differing approaches and regional variation in prescribing across England.

Julie Wood, Chief Executive, NHS Clinical Commissioners said in March 2017:

'Having national support from NHS England and the DH (Department of Health) for those local decisions means there will be more consistency and reduce variation for patients.

The health minister's preference following the consultation was to continue GFF on prescription but restrict products to breads 
"The immediate response to the Government's decision on GFF prescribing has been mixed.

and flour mixes. Key themes considered included accessibility and availability of GFF, cost of GFF, impact on adherence to a gluten-free diet, appropriate use of NHS resources, health inequalities, consequences of untreated coeliac disease and the potential for system abuse and wastage. The evidence was considered alongside the views of key stakeholders including clinicians, commissioners and patients.

The immediate response to the Government's decision on GFF prescribing has been mixed. Coeliac UK has welcomed the decision of a national approach to the availability of GFF on prescription, while a statement from the NHS Clinical Commissioners believes a missed opportunity has occurred to release entire GFF spending funds to other frontline NHS services. 8.9 Although regulations will be put in place to restrict the type of product that can be prescribed, CCGs will still be able to develop local policies that restrict prescribing further. Thus the current scenario of a postcode lottery where some patients are able to access prescriptions in line with the national approach while others have effectively no access may continue.

\section{CONSEQUENCES FOR PATIENTS AND THE NHS}

The long-term sequelae of restricting GFF prescriptions may take many years to reveal themselves with regards to patient outcomes. Adherence to a gluten-free diet is recognised to be difficult for people with coeliac disease, varying between $42-96 \%$, based on international adherence studies in both children and adults. ${ }^{3}$ This outcome may be influenced by access to GFF prescriptions. ${ }^{8}$ A previous NICE health economic analysis estimated that the cost of prescribing GFF was E194.24 per patient per year. ${ }^{10}$ This figure represented a low treatment cost for a lifelong autoimmune disease, which contrasted treatment costs associated with long-term complications such as osteoporosis, where an average fracture cost was $€ 27000 .{ }^{8}$ Unless the newly set out national policy is reflected across England patients may be at risk of long term complications. Only time will tell whether this concern will come to fruition.

Importantly, it should be recognised that this prescription debate has raised the profile of coeliac disease - a lifelong condition affecting $1 \%$ of the UK population. The average delay in diagnosis is 13 years, with individuals reporting on average 13 consultations with their GP prior to a diagnosis being established. ${ }^{11}$ In the UK, three out of four cases of coeliac disease remain unrecognised. Medical nihilism has for too long negatively influenced the outcomes of people with coeliac disease. Hopefully, through continued working between commissioning groups, patients, stakeholders and clinicians, an optimal use of available resources will be achieved, ensuring enhanced outcomes for these patients.

\section{Matthew Kurien,}

Senior Clinical Lecturer and Honorary

Consultant Gastroenterologist, Academic Unit of Gastroenterology, Departments of Infection and Immunity and Cardiovascular Science, University of Sheffield, Medical School, Sheffield; and Department of Gastroenterology, Royal Hallamshire Hospital, Sheffield Teaching Hospitals NHS Foundation Trust, Sheffield.

\section{Nick Trott,}

Specialist Gastroenterology Dietitian, Academic Unit of Gastroenterology, Departments of Infection and Immunity and Cardiovascular Science, University of Sheffield, Medical School, Sheffield.

\section{Sarah Sleet,}

Chief Executive of Coeliac UK, Coeliac UK, High Wycombe, Bucks.

\section{David S Sanders,}

Professor of Gastroenterology and NHS Consultant, Academic Unit of Gastroenterology, Departments of Infection and Immunity and Cardiovascular Science, University of Sheffield, Medical School, Sheffield; and Department of Gastroenterology, Royal Hallamshire Hospital, Sheffield Teaching Hospitals NHS Foundation Trust, Sheffield.

\section{Provenance}

Commissioned; not externally peer reviewed.

\section{Competing interests}

The author has declared no competing interests.

\section{ADDRESS FOR CORRESPONDENCE}

\section{David S Sanders}

Room P39, Department of Gastroenterology, Royal Hallamshire Hospital, Sheffield Teaching Hospitals NHS Foundation Trust, Glossop Road, Sheffield S10 2JF, UK.

\section{Email: david.sanders@asth.nhs.uk}

\section{REFERENCES}

1. Department of Health and Social Care. Availability of gluten-free foods on NHS prescription. [Consultation outcome]. 2018. https://uww.gov.uk/government/consultations/ availability-of-gluten-free-foods-on-nhsprescription (accessed 13 Jul 2018).

2. Coeliac UK in collaboration with The British Dietetic Association and the Primary Care Society for Gastroenterology. Gluten-free foods: a revised prescribing guide 2011. https:// unw.coeliac.org.uk/document-library/378gluten-free-foods-a-revised-prescribingguide/?return=/gluten-free-diet-and-lifestyle/ prescriptions/national-prescribing-guidelines/ laccessed 13 Jul 2018).

3. See JA, Kaukinen K, Makharia GK, et al. Practical insights into gluten-free diets. Nat Rev Gastroenterol Hepatol 2015; 12(10): 580-591.

4. Pinto-Sanchez MI, Verdu EF, Gordillo MC, et al. Tax-deductible provisions for gluten-free diet in Canada compared with systems for gluten-free diet coverage available in various countries. Can $J$ Gastroenterol Hepatol 2015; 29(2): 104-110.

5. NHS PrescQIPP (2015) Bulletin 69. NHS PrescQIPP Guidance on the prescribing of gluten-free foods. NHS PrescQIPP, 2015.

6. Kurien M, Sleet S, Sanders DS, et al. Should gluten-free foods be available on prescription? BMJ 2017; DOI: 10.1136/bmj.6810.

7. Clarifications and corrections: Food on prescription. Daily Mail 2015; 20 Nov: http:// unw.dailymail.co.uk/home/article-3326264/ Clarifications-corrections-Food-prescription. html (accessed 13 July 2018).

8. Coeliac UK. Document: Department of Health consultation response. 2018. https:// unw.coeliac.org.uk/document-library/4509department-of-health-consultationresponse/?return=/campaigns-and-research/ campaigning-on-health/national-campaignto-protect-gluten-free-prescribing-in-england/ laccessed 13 Jul 2018).

9. NHS Clinical Commisioner. NHSCC statement on the result of the Department of Health and Social Care consultation on the availability of gluten-free foods on NHS prescriptions. 2018. https://www.nhscc.org/latest-news/nhsccstatement-on-the-result-of-the-departmentof-health-and-social-care-consultation-onthe-availability-of-gluten-free-foods-on-nhsprescription/ (accessed 13 Jul 2018).

10. National Institute for Health and Care Excellence. Coeliac disease: recognition, assessment and management. NICE guideline [NG20]. September 2015. https://uww.nice.org. uk/guidance/ng20/evidence laccessed 13 Jul 2018).

11. Gray AM, Papanicolas IN. Impact of symptoms on quality of life before and after diagnosis of coeliac disease: results from a UK population survey. BMC Health Serv Res 2010; 10: 105. 